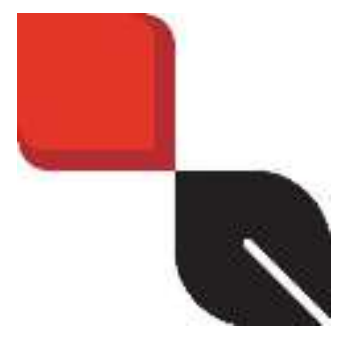

Cuadernos del CILHA n 34 - 2021 | publicación continua

ISSN 1515-6125 | EISSN 1852-9615

https://revistas.uncu.edu.ar/ojs3/index.php/cilha

CC BY-NC 2.5 AR

Recibido: 09/04/2021 Aprobado: 10/06/2021 |

PP. 1-18

DOI: https://doi.org/10.48162/rev.34.012

\title{
Suicidio feminicida y masculinidades culpables en Réquiem por Teresa de Dante Liano
}

\author{
Femicide-Suicide and Guilty Masculinities in Réquiem por Teresa \\ by Dante Liano
}

\author{
Ainhoa Vásquez Mejías \\ https://orcid.org/0000-0002-7747-8606 \\ Universidad Nacional Autónoma de México \\ ainhoavasquez@filos.unam.mx
}

México

\begin{abstract}
Resumen: La novela Réquiem por Teresa (2019) de Dante Liano refiere a un suicidio feminicida narrado desde la voz del hermano de la víctima. Este narrador homodiegético, inestable y borracho, permite develar las contradicciones del pensamiento heteropatriarcal, lo que se demuestra al criticar la violencia de género, pero, al mismo tiempo, ser él un hombre que la ejerce de manera simbólica. Asimismo, estas contradicciones se revelan en su oscilar entre la culpa por haberse mantenido al margen de las agresiones que sufría su hermana y la justificación por considerarse una masculinidad subordinada en relación con su cuñado. A pesar de que prima la autojustificación, el mismo narrador termina por reconocer que el crimen contra Teresa es responsabilidad de todos. La violencia de género y el resultado en un suicidio feminicida no es un problema doméstico e individual, sino social.
\end{abstract}


Palabras clave: Dante Liano, Literatura guatemalteca, Suicidio feminicida, Violencia de género, Masculinidades.

\begin{abstract}
The novel Réquiem por Teresa (2019) by Dante Liano is about a femicide-suicide narrated from the perspective of the victim's brother. The homodiegetic, unstable, and drunk narrator of the novel reveals the contradictions of heteropatriarchal thought. This becomes evident when he criticizes gender violence and also because he is a man who exercises violence in a symbolic way. In addition, these contradictions are revealed in his oscillation between the guilt that he feels for having remained at the margin of the aggressions that his sister suffered, and the way he excuses himself for not acting upon the aggressions since he considered that his own masculinity was subordinate to his brother-in-law's. Although self-justification prevails, the same narrator ends up recognizing that the crime against Teresa is everyone's responsibility. Gender violence and the result in a femicide-suicide is not a domestic and individual problem, but a social one.
\end{abstract}

Keywords: Dante Liano, Guatemalan Literature, Femicide-Suicide, Gender Violence, Masculinities.

\title{
Introducción
}

Dante Liano es un narrador guatemalteco, Premio Nacional de Literatura Miguel Ángel Asturias en el año 1991. Réquiem por Teresa es su última novela (2019) y, como él mismo señala en una entrevista concedida a Carlos Olivares (2019), su publicación era una deuda pendiente, pues la escribió hace más de veinte años "por una necesidad personal. La imaginación y la realidad se articulan en esta ficción [...] Esto es una historia que yo conozco y que me hirió en carne viva" (Olivares, 2019). La novela relata la vida y el suicidio de Teresa, la hermana del narrador. Casada desde muy joven con un militar, la mujer sufre un sinfín de agresiones físicas y sicológicas por parte de su esposo, lo que la orilla a acabar con su vida ante la vista de todos: amigos y familiares, que deciden no intervenir en la dinámica matrimonial y doméstica.

Si bien la novela narra una historia individual -el sufrimiento de Teresa- ha sido leída por la crítica, principalmente desde su aspecto alegórico, es decir, la vida privada de una mujer resulta ser la historia de Guatemala, de una época de poderío militar y de mucha violencia. Es, por ejemplo, la lectura de Víctor Daniel López (2019) quien indica

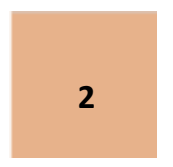


que el suicidio de Teresa es el suicidio colectivo del pueblo guatemalteco "que ha sufrido con los años su inseguridad, la revolución de 1944, y la situación actual que vive con el gobierno que tiene las riendas ahora, bajo el mandato de Jimmy Morales ${ }^{1}$, aquel que fue un comediante barato y payaso mediocre para convertirse en un títere más de la política guatemalteca" (López, 2019). Asimismo, señala que el imitador de Elvis, personaje que otorga el telón de fondo para las confesiones del narrador, puede ser visto como un reflejo del gobierno: "un héroe falso que se hace pasar por un ícono que es capaz de ganar fácilmente los corazones de la gente, que es capaz de fingirlo todo para poder aprovecharse de la sociedad mientras disfrutan de las canciones y la cerveza, aunque en realidad tengan un dolor insoportable por dentro" (López, 2019).

Una lectura similar propone Teresa Iniesta Orozco (2020), al señalar que Teresa representaría a todas las mujeres que viven bajo una dictadura militar y luchan para no sucumbir ante el poder patriarcal. Con ello, establece una relación directa entre la dictadura y la condición de sumisión que tienen las mujeres en Latinoamérica, vinculando lo privado con lo público. Asimismo, Dante Liano propone la posibilidad de leer a Teresa no sólo como una metáfora de la dictadura sino también de la conquista, tal como lo indica en una entrevista a Herles Velasco: "Este libro es una metáfora, Teresa funciona en ese sentido; no sólo hablando de América Latina, sino cualquier lugar que ha sido sometido a una colonización" (Velasco, 2019).

En este artículo propongo, en cambio, leer la novela desde la violencia de género que sufre Teresa y la complicidad machista de quienes la rodean, incluyendo al hermano narrador y testigo. Por supuesto, no podemos desconocer que en esta historia personal hay una historia colectiva que se entremezcla, la historia de violencia de Guatemala, de la conquista, de la dictadura militar; no obstante, Teresa no es una víctima política, sino una mujer que sufre violencia doméstica en un país: "con arraigadas concepciones y prácticas sociales que privilegian lo masculino en detrimento de lo femenino. Tales aspectos permiten tipificar a la sociedad guatemalteca como una sociedad machista, con las consiguientes condiciones de desigualdad de género que ello implica" (Díaz, 2013, p. 46).

\footnotetext{
${ }^{1}$ Presidente de la República de Guatemala hasta enero del año 2020. Miembro del partido Frente de Convergencia Nacional.
} 
En este sentido, concuerdo con las palabras de Dante Liano, quien refiere a esa violencia patriarcal estructural, que es la que propicia la violencia contra Teresa y la inacción de los personajes ante ella: "El machismo está enmarcado en una sociedad como la guatemalteca y asimismo, la violencia en contra de las mujeres. El centro de la novela tiene que ver con eso. La historia de Teresa es terrible y se va suscitando ante las miradas de los otros. Nadie interviene. El machismo está normalizado" (Olivares, 2019). Así, aunque la narración está situada en Guatemala, no resulta muy diferente a la realidad de casi cualquier país latinoamericano en que las mujeres viven un historial de abusos por parte de sus parejas y son asesinadas en sus propios hogares. Es también la historia de impunidad que rodea este tipo de casos en que, al cometer suicidio, no se considera a las parejas como culpables, a pesar de que en todos los aspectos es reconocible como suicidio feminicida.

Diana Russell (2006) fue una de las primeras feministas en proponer nombrar y tipificar el suicidio feminicida como un delito punible, pues hay mujeres que soportan un continuum de violencia, tanto por la sociedad patriarcal en la que se insertan, como por sus parejas masculinas y, frente a ello, son orilladas a quitarse la vida (Russell, 2006, p. 273). El término de la vida por decisión propia, entonces, no es realmente una decisión sino una salida ante los diversos tipos de violencia machista que sufren. En Latinoamérica, se ha suscitado también una discusión al respecto, puesto que no existe su tipificación ${ }^{2}$, aunque pareciera resultar clara la relación entre el suicidio o conductas suicidas y las mujeres que viven violencia doméstica (Morfín López y Sánchez-Loyo, 2015, p. 58).

Al no ser considerado como un delito punible es muy difícil saber su recurrencia, porque, tal como señala el informe "La perspectiva de género en los planes gubernamentales de prevención del suicidio en América Latina y el Caribe" (Guajardo et al., 2017), en la mayoría de los países latinoamericanos no se incluye la perspectiva de género en las estadísticas y se considera un problema de salud mental privado. Lo mismo ocurre con la violencia doméstica, que también es considerada un asunto familiar. Al respecto el informe de URNG: Feminicidio en Guatemala (2005), corrobora que "pese a ser generalizado, este problema había permanecido oculto durante siglos

\footnotetext{
${ }^{2}$ El único país latinoamericano que reconoce el suicidio feminicida como tipo penal es El Salvador, en que "se ha incorporado por ley la figura de suicidio feminicida por inducción" (Del Río Jiménez, 2017, p. 175).
} 
llegando a constituirse una violación de sus derechos normalizada y aprobada socialmente, que se reproduce en los patrones de convivencia familiares, institucionales y sociales en general" (p. 25).

De esta forma, tanto la violencia de género que viven las mujeres en sus hogares, como el resultado en suicidio, son considerados, muchas veces, como problemas privados en los que nadie debe intervenir o problemas de salud mental. Paulina Del Río Jiménez (2017), Presidenta de la Fundación José Ignacio en Chile, señala la importancia de empezar a visibilizar este tipo de situaciones comunes, que no deben seguir pensándose desde lo doméstico, sino como asuntos públicos que pueden prevenirse:

Cuando la asimetría del poder hombre-mujer deriva en abuso (del tipo que sea) siempre afecta psicológicamente a una mujer. Al ser sistemático y prolongado este abuso, va disminuyendo lentamente la autoestima de la mujer, reduciendo el espacio que ella siente que ocupa en el mundo y conduciéndola a un lugar en que ya no hay ninguna esperanza de cambio. Considerando que la desesperanza es uno de los principales predictores de suicidio y que la víctima probablemente está deprimida, y si a ello le sumamos un posible síndrome de estrés postraumático, nos encontramos frente a una bomba de tiempo. (p. 173)

Esto es lo que retrata Dante Liano en su novela: una serie de violencias hacia las mujeres, que se dan en el ámbito privado y que, por ello, se ocultan y se permiten sin que nadie se involucre para detenerlas. Así, aunque el culpable directo del suicidio feminicida de Teresa es el esposo, también el hermano se asume como cómplice de una sociedad machista que propicia este tipo de abusos por considerarse asuntos domésticos.

En el presente artículo se analizan los tipos de violencia (sicológica, física, económica) que sufre Teresa antes de acabar con su vida, violencias relatadas por su mismo hermano, lo que indica que él es testigo consciente de las agresiones ejercidas sobre ella. En la segunda parte, se reflexiona acerca de la importancia en la elección de este narrador homodiegético, pues esta subjetividad e inestabilidad (tanto en la propia voz en primera persona como en el hecho de que se va alcoholizando) permiten develar estas contradicciones y machismo de la sociedad guatemalteca. Así, oscila constantemente entre diversas actitudes: se justifica, se culpa, se victimiza, denuncia el 
sistema patriarcal, a la vez que él mismo ejerce una violencia simbólica contra las mujeres. Esta postura ambigua y, a veces, dicotómica, otorga un panorama completo de voces y pensamientos individuales y colectivos frente a la violencia de género.

\section{Un continuum de violencia con resultado en suicidio feminicida}

Resulta claro que el narrador, hermano de Teresa, conoce perfectamente los abusos y agresiones que sufrió antes de morir. Una historia de violencia física, simbólica y económica que terminan por mermar sus deseos de vivir y la conducen al suicidio. El primer episodio de violencia física ocurre poco tiempo después de que Teresa se ha casado con el Pirata. Él la golpea y Teresa llama a la casa de sus padres para pedir protección. Ni sus padres ni sus hermanos hacen nada para ayudarla. Este tipo de agresiones se encuentran actualmente consignadas como delito en la Ley contra el Femicidio y otras Formas de Violencia contra la Mujer, promulgada en Guatemala en el año 2008, como: “Acciones de agresión en las que se utiliza la fuerza corporal directa o por medio de cualquier objeto, arma o sustancia con la que se causa daño, sufrimiento físico, lesiones o enfermedad a una mujer" (Ley 2008), sin embargo, al considerarse que los asuntos domésticos son de discusión privada, muchas veces no se denuncian y el círculo cercano prefiere no involucrarse, tal como sucede en el caso de Teresa.

Esta violencia física que sufre, no obstante, no es el único tipo de abuso que debe soportar. El hermano supone, considerando los antecedentes de violencia y el carácter del Pirata que, cuando vivieron en México, él no la dejaba ni siquiera salir de su departamento. Asegura que era un hombre muy celoso y, por tanto, asume que Teresa debe haberse sentido muy sola, pero que, en cambio, él sí debía haber salido a beber con los amigos y esperar a que ella le curara la borrachera los sábados y domingos. Imagina a su hermana convertida en un objeto doméstico sin voluntad propia y obedeciendo a las órdenes del militar, en las tardes grises "lavando en la bañera las camisas blancas del militar impecable" (Liano, 2019, p. 61) y "tarde sin color preparar biberones, de leche derramada, sin sueños a la vista" (Liano, 2019, p. 62). Cosificada como parte del inmobiliario del departamento de México, a cargo exclusivamente del cuidado de la casa y las hijas.

Esta violencia simbólica que ejerce el esposo al convertirla en objeto se transforma más tarde en hostigamiento al poner a sus propias hijas en su contra. Señala el hermano que 
el padre trataba a sus hijas como novias hasta el punto de hacerlas sustitutos de Teresa: las llevaba a comer a los mejores restaurantes, los preferidos de Teresa, mientras a ella la dejaba en la casa; les compraba aquellas cosas que le gustaban a Teresa y ellas lo escondían en el armario o bajo la cama para que su madre no se enterara o tuviera acceso. Autos, vestidos, permiso para todo. Si ellas se ponían del lado de la madre, en cambio, las castigaba y humillaban como a Teresa: “¿Cómo le llamás a esto, cabrón, si no la tortura psicológica que fuiste aprender a Israel?" (Liano, 2019, p. 73). Este tipo de reflexiones del hermano nos permite entender que él era consciente del sufrimiento de Teresa.

La violencia sicológica que ejerce el Pirata sobre Teresa se manifiesta, asimismo, al demostrar su desilusión por procrear sólo mujeres. No obstante, cuando nace el varón y este muere, los abusos hacia ella se incrementan. Aunque el diagnóstico es claro al señalar que es muerte de cuna sin responsabilidad de nadie, el esposo la culpa ella: "Y el Pirata que alzó la vista y dijo una sola vez: 'Culpa tuya'. No le pudiste contestar. No le supiste contestar. Te tragaste el espanto de la acusación: descuidada" (Liano, 2019, p. 95). Este tipo de violencias sicológicas y emocionales, también han sido consignadas en la Ley contra el Femicidio y otras Formas de Violencia contra la Mujer. Se entiende por ellas:

aquellas acciones que pueden producir daño o sufrimiento, psicológico o emocional a una mujer, a sus hijas o a sus hijos, así como las acciones, amenazas o violencia contra las hijas, los hijos u otros familiares hasta el cuarto grado de consanguinidad y segundo de afinidad de la víctima, en ambos casos con el objeto de intimidarla, menoscabar su autoestima o controlarla, la que sometida a ese clima emocional puede sufrir un progresivo debilitamiento psicológico con cuadros depresivos. (Ley, 2008)

Si consideramos la actual Ley contra el Femicidio en Guatemala resulta evidente que Teresa es víctima, tanto física como sicológica, del maltrato de su esposo; agresiones que van mermando su estado emocional, su autoestima y le provocan cuadros depresivos con intentos de suicidio, antes de llegar a consumarlo. A estas violencias se suma también la económica, pues, como indica Donoso (2008), todo intento de las mujeres por salirse de los parámetros domésticos e incorporarse activamente a 
trabajos remunerados o actividades educativas, es decir, la conquista por su autonomía: "es percibida como una usurpación del espacio público por las mujeres y el deterioro de las obligaciones propias de lo privado -cuidado de los hijos, del hogar-con la consiguiente desintegración familiar" (p. 15).

Esto ocurre cuando Teresa decide estudiar. El hermano señala que a ella, desde pequeña, le encantaba leer y que su esposo le prohibía el dinero para comprar libros. Para evitar que lo gastara en eso, se lo restringía al pago justo de la comida y la sirvienta. De la misma manera, cuando ella manifiesta su intención de volver a estudiar, él le asegura que no hay dinero para esas cosas. Es esta la única vez en que la familia se involucra en los asuntos matrimoniales, ya que los padres deciden apoyarla económicamente, sin embargo, el Pirata la obliga a trasladar su estudio al baño: "Entre la taza del inodoro y la ducha, allí estaban su mesa y su lamparita. Eran la señal de la guerra que le hiciste para que no estudiara. Por eso, Pirata, el día que se graduó fue el día su victoria, y el primer día que comenzó a caminar con paso seguro hacia su muerte próxima" (Liano, 2019, p. 77).

Al asegurar que la victoria de la graduación fue también el primer día en que comenzó a caminar hacia su muerte, resulta evidente que el hermano es capaz de ver la violencia que está sufriendo Teresa y la coerción que el Pirata ejerce sobre ella. El problema de ello es que, lejos de considerarse un asunto de cuidado y contribuir a visibilizar la situación de desventaja en la que se encuentra como mujer, este tipo de actitudes se normalizan: "La normalización de la violencia -por tan excesiva que satura nuestra cotidianeidad hasta hacerla parte de una realidad 'inmodificable'- y la interiorización de la misma por las mujeres actúan articuladamente con el patrón de sumisión de las mujeres que impone la cultura patriarcal" (Donoso, 2008, p. 5). Así, tanto la familia como las mismas mujeres víctimas consideran que deben soportar todo tipo de violencias y humillaciones porque es lo común, incluso, lo que se espera de ellas en una cultura patriarcal.

Teresa, sumisa, objeto y víctima de todo tipo de violencias, presenta algunas tentativas de sublevación, algunas positivas, como el hecho de estudiar y graduarse, y otras negativas como el volverse cleptómana y llevar a cabo algunos intentos de suicidio. En ninguno de estos casos recibe más ayuda o atención de parte de su familia. Es así que 
la mujer tiene un último ensayo de rebelión -según la propia interpretación del hermano- en el hecho de decidir engañar al Pirata con su jefe, un militar de mayor rango y el vecino de enfrente: "el hombre más horrible de la Colonia Militar" (Liano, 2019 , p. 125). Sin embargo, frente a tanta violencia física y sicológica, esta infidelidad como venganza no alcanza para subsanar su autoestima y su ánimo, por lo que termina suicidándose: un suicidio feminicida.

Como señalaba anteriormente, el suicidio feminicida no está tipificado aún dentro de la Ley Contra el Femicidio y otras Formas de Violencia Contra la Mujer (2008), que tiene como objetivo

garantizar la vida, libertad, integridad, dignidad, protección e igualdad de todas las mujeres ante la ley, y particularmente cuando por condición de género, en las relaciones de poder o confianza, en el ámbito público o privado quien agrede, cometa en contra de ellas prácticas discriminatorias, de violencia física, psicológica, económica o sexual, o bien de menosprecio a sus derechos. Esta ley tipifica como femicidio la muerte de una mujer, provocada en el marco de las relaciones desiguales de poder entre hombres y mujeres, por su condición de mujer. Establece el delito de violencia contra la mujer como el acto provocado por un hombre en el ámbito público o privado mediante el cual se ejerza violencia física, sexual o psicológica en contra de la víctima. (Taracena, 2017, p. 113)

Sin embargo, aunque estamos ante una Ley muy completa en cuanto a todos los tipos de violencia que pretende penar, aún no se considera al suicidio como feminicidio. A pesar de los estudios que se han realizado al respecto (Donoso, 2008; Morfín López y Sánchez-Loyo, 2015; Asensi-Pérez, Borrell-Asensi y Díez-Jorro, 2019) que concuerdan en que muchos de los suicidios de mujeres son el desenlace del continuum de violencia que sufren (Donoso, 2008, p. 7), pues lo ven como una salida a esta situación de la que no es posible escapar de otra manera (Morfín López y Sánchez-Loyo, 2015, p. 60), todavía no se reconoce la importancia de visibilizar y tipificar como un caso especial de feminicidio: suicidio forzado o incitación a quitarse la vida (Asensi-Pérez, Borrell-Asensi y Díez-Jorro, 2019, p. 206). 
En el caso de la novela es clara esa serie de violencias de todo tipo que vive Teresa y de las que el hermano es capaz de darse cuenta. El narrador reflexiona que lo que le pasó a Teresa no fue por plena decisión personal sino el resultado de las agresiones constantes del Pirata: "Se dio en las manos una muchacha diáfana y nos has devuelto un cadáver. No la mataste con tus manos, cómo habría sido de ley por tu profesión de militar guatemalteco, la mataste de otro modo, de la manita la llevaste a la degradación, a la monstruosidad irreconocible, al punto que yo me decía: está que veo ahora no es mi hermana, esta mujer es otra persona" (Liano, 2019, p. 71). Esta declaración, que parece tan contundente respecto a la responsabilidad del Pirata, no es aplicable a él mismo. Este narrador inestable y borracho oscila, en cambio, entre la lucidez y la crítica al machismo y la compasión hacia sí mismo, entre la denuncia de las condiciones en las que su hermana debió vivir y una violencia simbólica que él mismo ejerce sobre ella y otras mujeres. El narrador encarna las contradicciones de esta sociedad patriarcal.

\section{Las contradicciones de un pensamiento machista}

Contar una historia desde un narrador homodiegético, señala la académica Luz Aurora Pimentel (1998), nunca es una elección banal o arbitraria. El narrador en primera persona tiene un alto grado de subjetividad, al contrario de un narrador heterodiegético que nos otorga a los lectores una mayor confiabilidad. El narrador que participa en el mundo diegético se involucra en la historia, le afecta de alguna manera, por ello no podemos esperar una narración plenamente fidedigna, pues esa subjetividad "colorea y deforma la información que sobre ese mundo nos proporciona" (Pimentel, 1998, p. 140). A esta inestabilidad intrínseca de los narradores homodiegéticos, se suma, en este caso, la elección de un narrador que, además, está borracho.

Se propone, por tanto, que el uso de este narrador permite mostrar las contradicciones individuales del personaje respecto a los hechos que desembocaron en el suicidio de Teresa, pero estas resultan un espejo de las contradicciones sociales. Este narrador a menudo transita entre la autocompasión y la culpabilidad, entre la denuncia de las agresiones ejercidas contra su hermana y la complicidad con una sociedad machista. Así, tenemos un narrador poco confiable pero que es capaz de manifestar su inconsciente, sus ideas, por más dispares que nos parezcan. El mismo narrador menciona en un momento: “¿Qué sabes vos de mí, de lo que verdaderamente siento, 
de lo que verdaderamente soy? ¡No lo sé yo lo vas a saber vos!” (Liano, 2019, p. 80). Con esta afirmación nos invita a desconfiar de lo que él mismo piensa o siente.

Este narrador inestable parece tener muy claro que su hermana se suicidó porque no aguantó más la violencia de su esposo. Parece no tener tan claro, en cambio, la responsabilidad que le cabe en ello. El narrador parte por justificarse, pues asume que él es una masculinidad subordinada en comparación al Pirata, a quien describe como hegemónica (Connell, 1995). Mientras el narrador es temeroso, débil y, por tanto, no violento, el esposo de la hermana exhibe conductas violentas y delincuenciales. Desde niño, señala el narrador, el Pirata ejerce esa hegemonía, demuestra su valentía y hombría golpeando a otros hombres y emborrachándose:

El pirata se desahogaba con algún otro machito que le estuviera disputando el puesto de jefe de la pandilla. Se emborrachaba el Pirata, con sus cuates, y luego terminaban en el campito, insultándose al principio y pegándose después. Eso era ser hombres, eso era ser hombres para todos nosotros, eso era ser hombres en Guatemala de la Asunción, eso era ser hombres en un puntito del universo: escupir sangre y polvo, tragar sangre y polvo, masticar la tierrita mientras los otros consideraban que era suficiente, que ya nos podían separar, y nosotros todavía luchando por desembarazarnos, más serios todavía con los golpes y el deseo de matar. (Liano, 2019, p. 19)

El hermano de Teresa confirma que ser hombre es ser violento, alcohólico y poderoso. No dejar que otros sean superiores o líderes. Además, indica que el Pirata no tenía miedo a nadie ni a nada, que jamás lo vio humillarse o pedir perdón, que el Pirata no perdía nunca. Por el contrario, el narrador se define como alguien inestable, que no sabe quién es, que no es capaz de expresar lo que piensa o siente mediante las palabras adecuadas y que, además, se sitúa en el lado de los perdedores: "Ha de ser el gusto de perder siempre, la pura animalada de ir contra la corriente, del lado del perdedor" (Liano, 2019, p. 31).

La primera vez que el Pirata golpea a Teresa él decide no interponerse apelando a esta masculinidad subordinada. Se define a sí mismo como chaparro, débil y cobarde, por lo que asegura que, de haber intervenido, el cuñado lo hubiera destrozado o se hubiera reído de él, pues no tenía la fuerza para sostenerse a sí mismo (Liano, 2019, p. 37). 
Todo en este discurso es una justificación. Justificación por no estar a la altura de una hombría que podría disputar con esa masculinidad hegemónica, justificación por no haber sido capaz de defender a Teresa y justificación porque él es un civil en comparación al militar poderoso: "¿Y qué voy a pedir, yo, civil desarmado, ante la personificación del poder, hombre de escuadra y guardaespaldas, bien zampado en el mero centro del Estado Mayor?" (Liano, 2019, p. 72).

Esa masculinidad subordinada, en otros contextos en cambio, se convierte en hegemónica en el sentido de degradar a las mujeres. Él, tan cauto y miedoso del Pirata, con las mujeres actúa de manera completamente opuesta, cosificándolas y juzgándolas. Esto demuestra que la hombría se mide en comparación a otros varones, sin embargo, cualquier hombre, incluso quien se define desde la subordinación, es susceptible de manifestar actitudes machistas en los espacios que comparte con mujeres. Por ejemplo, mientras se encuentra en el bar, el narrador repara en las jóvenes que están promocionando cervezas y se refiere a ellas como "Culitos bien con cara de en qué me he metido" (Liano, 2019, p. 17).

No sólo con desconocidas el narrador demuestra su misoginia. También, a menudo, describe a su madre y a su hermana desde los estereotipos de género. Ejerce violencia simbólica y epistémica contra la madre, por ejemplo, al culparla de lo que le ocurre a Teresa, a la vez que la cuestiona por ser fuerte y decidida. Coherente con ello, ve a su padre como un macho subordinado al carácter de su esposa, débil y pasivo: "Me acuerdo una vez, que parecen varias veces, está mi mamá tirada en el suelo, gritando, con un ataque histérico, gritando y pataleando de la pura cólera, y nosotros aterrados, puros patojos ante la locura de los adultos, y todo era porque el viejo había llegado a las dos de la mañana después de una parranda" (Liano, 2019, p. 41). Para el narrador, así, resulta normal que su padre, como hombre, llegara en la madrugada borracho después de una fiesta y, al contrario, la madre es la culpable por recriminarlo. Frente a estos episodios el narrador se expresa de la madre en términos sexistas como "histérica", "celosa" e indica que le hubiera gustado exigirle al padre "que sea hombre" (Liano, 2019, p. 42).

Lo mismo ocurre cuando se refiere a su hermana Teresa, ya que al describirla desde niña insiste en reiteradas ocasiones que Teresa siempre lloraba sin razón. Podríamos 
señalar que, así como tacha a la madre de histérica y celosa, también realiza una especie de gaslighting hacia su hermana, pues indica que su llanto es injustificado, minimiza sus emociones $\mathrm{o}$, al menos, nunca se pregunta o se preocupa por aquello que le afectaba: "Era como una sirena el llanto insistido de la Teresa, se callaba un momento y luego volvía con más ganas, entre pujidos y mocos [...] ¿Por qué chingados lloraba tanto? Yo no me acuerdo" (Liano, 2019, p. 25). Esto se convierte también en una violencia simbólica hacia la hermana, porque no sólo la describe como una niña llorona sin razón, sino que indica que, de alguna manera, estaba destinada a la vida que le tocó vivir y a sufrir esa violencia, pues: "Todo lo que cantara al fracaso, a la vida desperdiciada y hundida en un tonel de mierda, eso le gustaba" (Liano, 2019, p. 22). Además, la define como una perfecta mujer de militar por su maquillaje exagerado, la ropa cara, los labios rojos. La califica de inocente, ingenua y tontona, se burla de sus intereses y sus gustos.

Esa incapacidad por entender quién era su hermana provoca que la vea a través de estereotipos. Por ejemplo, asume que el momento en que Teresa fue más feliz fue cuando tuvo a su primera hija porque era un amor nuevo complementario al que sentía por el Pirata e insiste en que ella lo seguía queriendo a pesar de las borracheras y las palizas. También la acusa de haberse embarazado a propósito del último hijo para salvar su matrimonio. Frente a la falta de la Teresa real, a quien ya jamás podrá conocer, se imagina a una Teresa desde los clichés de género. No cree que pudiera tener más sueños que casarse, tener hijas, tener dinero. A la par, la juzga cuando decide tomar otros caminos que no son consecuentes con ese modelo que él se crea. La considera mala madre porque no le dio suficiente atención a sus hijas y la recrimina por su comportamiento sexual al retratar el amorío que tuvo con el jefe del Pirata. Esto se extiende también al hermano menor quien la juzga e indica que cuando la encontraron estaba vestida como puta, porque tenía una blusa que terminaba en el ombligo y unos pantalones cortos "con todas las baratijas puestas" (Liano, 2019, p. 120).

Reconocemos lo difícil que es subsanar este tipo de contradicciones, pues habitamos en una sociedad en que hemos internalizado la cultura patriarcal y, por ello, resulta casi imposible sustraernos de comportamientos que hemos aprendido durante toda la vida. El narrador, así, mientras se inserta, en muchos aspectos, en un pensamiento heteropatriarcal, juzgando a su madre como histérica, a su padre como poco hombre, a su hermana desde los estereotipos, también es capaz de ver las deficiencias del 
sistema y criticar esa sociedad en la que se ha desenvuelto. Critica la falta de oportunidades que tienen las mujeres, las condiciones desiguales en las que tienen que competir, las ideas preconcebidas, etc. Todo ello en lo que él mismo cae, pero que parece sencillo poder ver en otros hombres. Dentro de este espíritu crítico cuenta que la mamá se ganó una beca para estudiar en la capital cuando terminó la primaria, pero que su propia madre no le dio permiso: "a su mamá le dio miedo de que se volviera puta en la capital, me entendés, y no le dio el mierda permiso para sacar el título de maestra, te das cuenta iNo le dieron permiso! Y se quedó zampada en el abismo de la provincia" (Liano, 2019, p. 32). Esta historia de la mamá sirve para referir la historia de Teresa porque asegura que Teresa nació señalada para repetir la historia, tal como todas las mujeres de su época y de su condición económica: "Nacer en el lugar equivocado, en la época equivocada, la familia equivocada, en la clase equivocada, con el sexo equivocado" (Liano, 2019, p. 33).

El hermano es consciente de que Teresa no tenía muchas opciones en la vida por haber nacido mujer e, incluso, entiende que Teresa, más que casarse por amor, se casó joven y con el Pirata porque lo único que quería era salir de la casa paterna. El escenario de las mujeres es común. Lo doméstico se convierte en una cárcel en el que ellas pasan de la casa de la familia de los padres a la del marido sin posibilidades de ser libres, al contrario de lo que ocurre con los hombres que nacen para ser líderes y ser obedecidos y, por ello, son incapaces de controlarse cuando alguien los desafía. Es lo que intuye que ocurrió con Teresa: "al Pirata le debe de haber agarrado el terror del poder. El terror de la persona acostumbrada a mandar cuando alguien no le obedece: ¿y ahora qué hago? El pirata solo conocía una forma de convencer: rompiéndole la cara a los demás". (Liano, 2019, p. 50). Ante estos dos escenarios tan desiguales, de hombres que esperan ser obedecidos y mujeres encarceladas, el narrador reflexiona que el suicidio es un destino común entre las mujeres que no ven salida a esa vida injusta y monótona.

El narrador se nos presenta como un sujeto inestable y cargado de contradicciones. Aunque por momentos presenta la suficiente claridad para determinar que el suicidio de Teresa es culpa de la violencia que el Pirata ejerció sobre ella y reconocerle cualidades como el esfuerzo y el amor por el estudio, parece que no puede evitar caer en una violencia simbólica contra ella al calificarla también desde los estereotipos e, incluso, culpar a la mala suerte por su destino. Reflexiona que el Pirata era un hombre 
que traía mala suerte, amigo de la muerte: "no hay modo de que se muera él por eso se mueren los que lo rodean" (Liano, 2019, p. 23). Esta justificación al suicido de Teresa, desde la mala suerte, invisibiliza la violencia ejercida contra la mujer, así como su propia responsabilidad como hermano apático ante las agresiones.

Como parte de esa vacilación en otros momentos, en cambio, se aleja de las justificaciones y asume su culpa. Sabe, por ejemplo, que debió hacer algo la primera vez que Teresa les dijo que su esposo le había pegado: "Yo debí intervenir la primera vez que le pegó el Pirata. Eran los primeros meses de matrimonio, me recuerdo. Llamó a casa llorando y le contó a mi mamá que le había pegado el hombre" (Liano, 2019, p. 37). No obstante, se refugia en el mito patriarcal de que "Nadie debe meterse cuando el hombre agrede a su mujer", pues, según el informe Investigación sobre el femicidio en Guatemala: "La violencia doméstica es visualizada como un asunto privado, ámbito del cual se excluye toda noción de derechos. La familia ha estado por encima de las garantías y bienestar de sus integrantes" (URNG, 2005, p. 30). Justifica su desidia en relación con esta máxima patriarcal de no intervenir en los asuntos privados ${ }^{3} \mathrm{y}$, $\operatorname{como}$ ya he señalado, en su comparación como varón subordinado frente al macho hegemónico que representa para él el Pirata.

Ese connato de culpa termina en justificación y también en victimización. Más allá de haberse convertido en una masculinidad cómplice (Connell, 1995) pareciera que es él la víctima por el dolor que siente ante la pérdida de la hermana. De esa forma describe su sufrimiento: "Era como si el mundo te hubiera sido sustraído, como si tu mundo hubiera sido cambiado por otro mundo lleno de vidrios quebrados, de espejos deformes, de cuchillos que cortaban los pies desnudos" (Liano, 2019, p. 54). No obstante, nuevamente la inestabilidad del narrador se presenta en una suerte de desdoblamiento en que se ve a sí mismo como un sujeto ridículo por sentirse así y expresa: "la sospecha de que estamos llorando por nosotros, por el gustito de moquear,

\footnotetext{
${ }^{3}$ Resulta interesante preguntarse si es que bajo la actual Ley de Femicidio no hubiera sido considerado efectivamente culpable. Según Díaz (2013), en Guatemala, la "Ley para prevenir, sancionar y erradicar la violencia intrafamiliar define a esta como cualquier acción u omisión, por parte de parientes o conviviente o ex conviviente, que cause daño físico, sexual, psicológico o patrimonial a un miembro de la familia" (p. 47). Como pariente su deber hubiera sido denunciar las situaciones de violencia que vivía su hermana, al no hacerlo incurre en complicidad de violencia familiar por omisión.
}

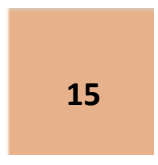

Cuadernos del CILHA n $34-2021$ 
una estética de tercer mundo, una cámara que nos filma desde afuera y nos hace ver con la máscara regada por las lagrimuchas, para que diga: vean qué sensible, qué delicado, cómo llora por su hermana" (Liano, 2019, p. 91). Esta voz homodiegética no deja de oscilar entre la justificación, la culpa, la victimización y la burla a sí mismo.

\section{Conclusiones}

Réquiem para Teresa es la historia de la violencia reiterada que sufre una mujer en manos de su esposo. Es la historia de un suicidio feminicida, puesto que Teresa es orillada a acabar con su vida producto de las agresiones físicas y sicológicas constantes a la que es sometida. También es la historia del hermano, quien es perfectamente capaz de entender y apuntar el callejón sin salida en el que su hermana se encontraba y, sin embargo, es incapaz de evitar su muerte. Esta incapacidad se deriva de sus propias contradicciones, pues, a la vez que denuncia la precariedad económica y emocional que Teresa vivió, ejerce sobre ella, sobre su madre y sobre las mujeres en general una violencia simbólica al recriminarlas por salirse de los parámetros establecidos por la sociedad patriarcal. Contradicciones que se manifiestan, asimismo, en el oscilar constante entre la culpa por no haber hecho nada, la victimización por su propio sufrimiento ante la pérdida familiar y la justificación por no haber querido involucrarse en asuntos matrimoniales o haber temido ante la masculinidad hegemónica del cuñado.

Este narrador inestable, borracho, que divaga durante toda la novela, permite entender los múltiples aspectos que convergen, tanto individual como socialmente, en un caso de violencia de género y suicidio: la culpa y la justificación, la pregunta de si esto pudo evitarse y cuál es el grado de responsabilidad que le compete a cada espectador. Predomina la autojustificación y prevalece la violencia simbólica hacia las mujeres. En ese sentido, el final que siembra la duda respecto a si fue suicidio o feminicidio es un último intento del narrador por borrar su participación en el desenlace fatal de la hermana y terminar de incriminar por completo al esposo para no tener que ver nuevamente sus errores: “¿Y si el pirata la hubiera matado? ¿Y si hubiera arreglado todo para que pareciera un suicidio? ¿Qué le cuesta matar a un militar en Guatemala? ¿Qué juez va a meter preso a un militar en Guatemala? (Liano, 2019, p. 57). El padre Cirilo Fuentes confirma la idea de que pudo haber sido asesinada y el hermano menor refuerza que el Pirata se interpuso durante la autopsia y dio órdenes al médico respecto a lo que tenía que escribir en el informe forense.

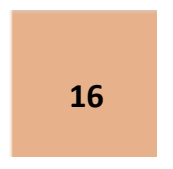


Más allá de un intento por tranquilizar la conciencia al pensar que su muerte no pudo evitarse si fue un feminicidio y no un suicidio, esta pregunta resulta banal. El suicidio de Teresa es un suicidio feminicida cuyo principal responsable es el esposo, ya que sometió a Teresa a un continuum de violencia física y sicológica que terminaron por mermar su autoestima y deseo de vivir. El Pirata, sin embargo, no es el único culpable. El hermano también lo es en la medida en que desde niño ejerció violencia simbólica sobre ella al ser incapaz de comprender sus emociones, al subestimarla, al ridiculizarla, al criticarla, al juzgar a la madre, al cosificar a las mujeres, al considerar que la violencia que vivía Teresa era un asunto privado.

Frente a un suicidio feminicida no hay un único imputable, la sociedad entera se pone en jaque y las responsabilidades deben ser compartidas. Esta parece ser la conclusión del propio narrador: "Porque si hay culpa, es de todos, y no hay remedio para nadie. A todos se nos murió la Teresa en la cara" (Liano, 2019, p. 116). La vacilación constante del narrador termina decantándose, en esta sentencia, por la propia culpa, por el asumir su rol en la muerte de la hermana. Así, la novela termina por plantear que, a pesar de querer invisibilizar la violencia y exculparnos cuando ello ocurre ante nosotros, el suicidio feminicida es probablemente uno de los crímenes más complejos porque no existe sólo un responsable. El suicidio es un asunto público, no doméstico y privado. Esto parece entender, finalmente, el narrador al asumirse cómplice del patriarcado por guardar silencio, mirar hacia otro lado y dejar que su hermana muriera, como él dice, en su propia cara.

\section{Referencias}

Asensi-Pérez, L., Borrell-Asensi, J., Díez-Jorro, M. (2019). Violencia contra la mujer y suicidio femenino. En S. Rivas (Ed.). El delito de feminicidio en el ordenamiento jurídico peruano, (pp.203-227). Instituto Pacífico.

Connell, R. (1995). La organización social de la masculinidad. En T. Valdés, J. Olavarría, Masculinidad/es: poder y crisis, (pp. 31-48). Ediciones de las mujeres.

Del Río Jiménez, P. (2017). Entrevista a Paulina Del Río Jiménez. En G. Guajardo, V. Cenitagoya, Femicidio y suicidio de mujeres por razones de género. Desafíos y aprendizajes en la Cooperación Sur-Sur en América Latina y el Caribe, (pp.173-176). FLACSO-Chile.

Díaz Castellanos, G. (2013). Violencia contra la mujer en Guatemala. Sociedad y Discurso, 23, 44-59.

https://doi.org/10.5278/ojs..v0i23.913

Cuadernos del CILHA n $34-2021$ 
Donoso, S. (2008). Feminicidio en Guatemala: las víctimas de la impunidad. Revista D'Estudis de la Violencia, 4, 1-23. https://dialnet.unirioja.es/servlet/articulo?codigo=2549942

Guajardo, G., Cenitagoya, V., Ortiz Tribiños, A., Adasme Pinto, J.C. (2017). La perspectiva de género en los planes gubernamentales de prevención del suicidio en América Latina y el Caribe. En G. Guajardo, V.

Cenitagoya, Femicidio y suicidio de mujeres por razones de género. Desafíos y aprendizajes en la Cooperación Sur-Sur en América Latina y el Caribe , (pp.157-172). FLACSO-Chile.

Iniesta Orozco, T. (23 abril 2020). Réquiem por Teresa de Dante Liano. Club de Lectura.

https://airenuestro.com/2020/04/19/club-de-lectura-requiem-por-teresa-de-dante-liano/

Liano, Dante. (2019). Réquiem por Teresa. Fondo de Cultura Económica.

López, V. D. (25 octubre 2019). Reseña de Réquiem por Teresa de Dante Liano. Revista Alegato. http://alegato.com.mx/2019/10/25/resena-de-requiem-por-teresa-de-dante-liano/

Morfín López, T. y Sánchez-Loyo, L. M. (2015). Violencia doméstica y conducta suicida: relatos de mujeres sobre la violencia y sus efectos. Acta Universitaria, 25, 57-61. https://doi.org/10.15174/au.2015.886

Olivares, C. (24 septiembre 2019). Presenta Dante Liano un retrato de la Guatemala machista y violenta. La Razón. https://www.razon.com.mx/cultura/presenta-dante-liano-un-retrato-de-la-guatemala-machista-yviolenta-requiem-por-teresa-elvis-presley-guatemala/

Pimentel, L. A. (1998). El relato en perspectiva. Siglo XXI Editores/UNAM.

Russell, D. (2006). Feminicidio: un coloquio internacional. En D. Russell, R. Harmes, Feminicidio: una perspectiva global, (pp.265-280). UNAM, Centro de Investigaciones Interdisciplinarias en ciencias y Humanidades.

Taracena, D. A. (2017). Atención integral a mujeres víctimas de violencia durante el proceso judicial penal en Guatemala. En G. Guajardo, V. Cenitagoya, Femicidio y suicidio de mujeres por razones de género. Desafíos y aprendizajes en la Cooperación Sur-Sur en América Latina y el Caribe, (pp.111-138). FLACSOChile.

URNG. (2005). Feminicidio en Guatemala: Crímenes contra la humanidad. Unidad Revolucionaria Nacional Guatemalteca. https://www.corteidh.or.cr/tablas/25828.pdf

Velasco, H. (24 diciembre 2019). La literatura es un juego: Entrevista con Dante Liano. + Cultura. http://mascultura.mx/la-literatura-es-un-juego-entrevista-con-dante-liano/ 